\title{
PERBEDAAN PREFERENSI KONSUMEN GENERASI Z ANTARA COFFEE SHOP BESAR DAN COFFEE SHOP KECIL DI KECAMATAN COBLONG KOTA BANDUNG
}

\author{
THE DIFFERENCES OF GENERATION Z CONSUMER PREFERENCES AMONG \\ BIG COFFEE SHOP AND SMALL COFFEE SHOP IN COBLONG, BANDUNG CITY
}

\author{
Desty Nadirah Putri*, Yosini Deliana \\ Program Studi Agribisnis Fakultas Pertanian Universitas Padjadjaran \\ Jalan Raya Jatinangor Sumedang Km. 21 \\ *E-mail: destynp09@gmail.com \\ (Diterima 17-09-2019; Disetujui 12-11-2019)
}

\begin{abstract}
ABSTRAK
Konsumsi kopi di Indonesia terus mengalami peningkatan pada tahun 2014-2018, sehingga membuat pengusaha tertarik untuk mendirikan coffee shop dengan klasifikasi yang berbeda-beda. Banyaknya usaha yang bergerak dibidang serupa menimbulkan persaingan antar pengusaha coffee shop. Salah satu upaya dalam menghadapi persaingan yaitu dengan cara mengetahui preferensi konsumen agar dapat membentuk segmentasi pasar yang tepat. Perkembangan gaya hidup dan pola pikir membuat hampir semua generasi pernah meminum kopi termasuk generasi $Z$, yaitu konsumen termuda yang potensial karena memiliki karakteristik yang unik. Kelurahan Lebak Gede merupakan tempat aktivitas para generasi $\mathrm{Z}$ karena terdapat banyak coffee shop dan dekat dengan sekolah ataupun universitas. Tujuan penelitian ini yaitu mengidentifikasi karakteristik konsumen kopi generasi $Z$ berdasarkan demografi, psikografi, atribut coffee shop, dan mengidentifikasi perbedaan antara konsumen coffee shop besar dan coffee shop kecil. Pemilihan sampel dalam penelitian ini menggunakan teknik systematic random sampling dengan sampel sebanyak 88 pada coffee shop besar dan 68 pada coffee shop kecil. Analisis yang digunakan adalah analisis deskriptif, dan analisis diskriminan. Hasil penelititan menunjukkan bahwa terdapat perbedaan yang signifikan pada karakteristik usia, intensitas minum kopi per minggu, waktu di coffee shop, dan jam berkunjung ke coffee shop.
\end{abstract}

Kata kunci: preferensi konsumen, generasi z, coffee shop, analisis diskriminan

\section{ABSTRACT}

Coffee consumption in Indonesia continues to increase in 2014-2018, making entreprereneurs interested in establishing coffee shops with different classifications. The number of businesses engaged in similar fields has led to competition among coffee shop entrepreneurs. One effort in facing competition is by knowing consumer preferences in order to form the right market segmentation. Lifestyle developments and mindset make almost all generations ever drink coffee including generation $Z$, which is the youngest potential consumer because it has unique characteristics. Kelurahan Lebak Gede is a place of activity for the $Z$ generation because there are many coffee shops and close to schools or universities. The purpose of this study is to identify the characteristics of generation $Z$ coffee consumers based on demographics, psychography, coffee shop attributes, and identify differences between large coffee shop consumers and small coffee shops consumers. The selection of samples in this study used systematic random sampling techniques with a sample of 88 at a large coffee shop and 68 at a small coffee shop. The analysis used is descriptive analysis, and discriminant analysis. The research results show that there are significant differences in the characteristics of age, consumption intensity, time spent in the coffee shop, and visiting time.

Keywords: consumer preference, generation z, coffee shop, discriminant analysis 


\section{PENDAHULUAN}

Kopi merupakan komoditas unggulan pertanian yang memiliki nilai ekonomis cukup tinggi. Popularitas kopi meningkat tajam hingga saat ini. Pebisnis kopi pun bermunculan dan coffee shop pun terus bertambah setiap tahunnya.

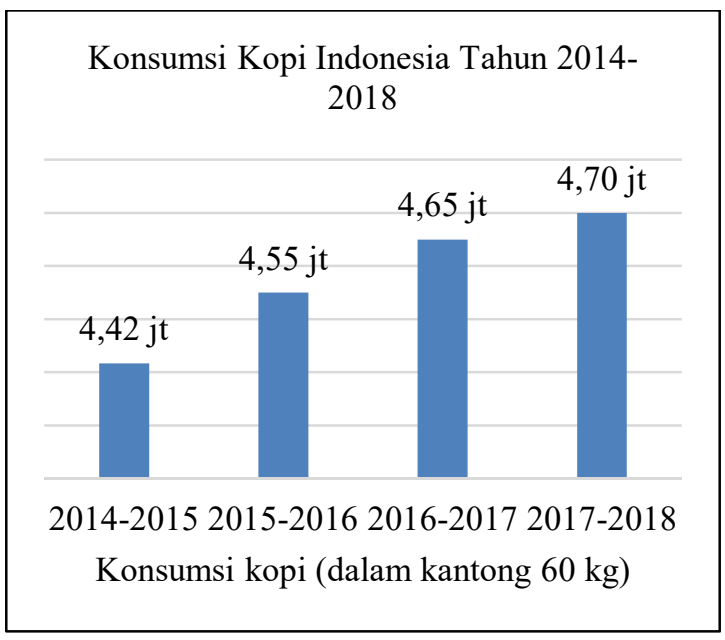

Gambar 1. Konsumsi Kopi Indonesia Tahun 2014-2018

Sumber : International Coffee Organization, 2018

Gambar 1 di atas menunjukkan terjadi peningkatan konsumsi kopi di Indonesia tahun 2013-2017. Peningkatan konsumsi kopi tersebut dikarenakan gaya hidup masyarakat yang berubah diikuti dengan tren kopi yang terus meningkat.

Coffee shop memiliki fasilitas yang berbeda-beda tergantung modal dan keinginan pengusaha dalam membuka coffee shopnya. Pada umumnya, terdapat coffee shop yang memiliki fasilitas lengkap, seperti adanya free wireless network, toilet, pendingin ruangan, interior yang menarik, pemandangan dan lainnya, hingga coffee shop yang hanya memiliki sedikit fasilitas. Essay Coffe dan Lo.Ka.Si Coffee and Space pun memiliki fasilitas yang berbeda sehingga dikategorikan ke dalam klasifikasi berbeda yang dapat diklasifikasikan menurut perusahaan kecil dan besar.

Tabel 1. Klasifikasi Perusahaan

\begin{tabular}{|l|l|}
\hline \multicolumn{1}{|c|}{$\begin{array}{c}\text { PERUSAHAAN } \\
\text { KECIL }\end{array}$} & \multicolumn{1}{c|}{$\begin{array}{c}\text { PERUSAHAAN } \\
\text { BESAR }\end{array}$} \\
\hline $\begin{array}{l}\text { Umumnya dikelola } \\
\text { oleh pemiliknya }\end{array}$ & $\begin{array}{l}\text { Biasanya dikelola } \\
\text { bukan oleh } \\
\text { pemiliknya }\end{array}$ \\
\hline $\begin{array}{l}\text { Struktur organisasi } \\
\text { sederhana }\end{array}$ & $\begin{array}{l}\text { Struktur } \\
\text { organisasinya } \\
\text { kompleks }\end{array}$ \\
\hline $\begin{array}{l}\text { Hubungan pemilik } \\
\text { dengan karyawan } \\
\text { dekat }\end{array}$ & $\begin{array}{l}\text { Pemilik hanya } \\
\text { mengenal sedikit } \\
\text { karyawan }\end{array}$ \\
\hline $\begin{array}{l}\text { Persentase kegagalan } \\
\text { perusahaan tinggi }\end{array}$ & $\begin{array}{l}\text { Persentase kegagalan } \\
\text { perusahaan rendah }\end{array}$ \\
\hline $\begin{array}{l}\text { Kurangnya tenaga } \\
\text { manajer yang andal }\end{array}$ & $\begin{array}{l}\text { Banyak manajemen } \\
\text { handal }\end{array}$ \\
\hline $\begin{array}{l}\text { Sulit memperoleh } \\
\text { modal jangka panjang }\end{array}$ & $\begin{array}{l}\text { Modal jangka } \\
\text { panjang biasanya } \\
\text { relatif mudah } \\
\text { diperoleh }\end{array}$ \\
\hline
\end{tabular}

Sumber: Fuad, dkk, 2001

Pada Tabel 1 di atas Essay Coffee termasuk ke dalam klasifikasi coffee shop kecil dan Lo.Ka.Si Coffee and Space termasuk klasifikasi coffee shop besar dikarenakan kedua coffee shop memenuhi klasifikasinya masing-masing.

Pada saat ini generasi $\mathrm{Z}$ menjadi topik yang menarik untuk dipelajari. Menurut Elizabeth T. Santosa (2015) generasi $\mathrm{Z}$ adalah generasi konsumen paling muda, yaitu generasi yang lahir pada tahun pertengahan 1995 sampai 2010, generasi ini lahir saat internet mulai 
masuk dan berkembang pesat dalam kehidupan manusia. Pada saat ini, pengusaha harus mempersiapkan diri untuk terlibat dengan generasi $\mathrm{Z}$ karena mereka merupakan konsumen yang potensial untuk saat ini dan masa depan.

Konsumen yang datang ke coffee shop dapat memiliki tujuan yang berbeda. Sehingga segmentasi demografis dan psikografis sangat diperlukan untuk mengetahui preferensi konsumen guna memahami keinginan dan kebutuhan konsumen agar perusahaan dapat melayani konsumennya dengan baik dan menciptakan suatu kepuasan untuk konsumen itu sendiri. Berdasarkan pemaparan $\mathrm{d}$ iatas, tujuan penelitian ini adalah untuk mengetahui perbedaan karakteristik dan preferensi konsumen kopi generasi $\mathrm{Z}$ antara Essay Coffee dan Lo.Ka.Si Coffee and Space.

\section{METODE PENELITIAN}

Penelitian ini dilakukan di Essay Coffee dan Lo.Ka.Si Coffee and Space Kelurahan Lebak Gede, Kecamatan Coblong, Kota Bandung. Pemilihan lokasi ini dilakukan secara sengaja (purposive), dengan pertimbangan kedua coffee shop merupakan coffee shop dengan klasifikasi coffee shop kecil dan coffee shop besar.
Penelitian ini menggunakan desain deskriptif kuantitatif, yaitu mendeskripsikan atau menggambarkan karakteristik dan preferensi konsumen dengan mengelompokkan konsumen coffee shop menurut klasifikasi coffee shopnya. Metode yang digunakan dalam penelitian ini adalah metode survey, yaitu penelitian yang dilakukan dengan menggunakan angket atau kuesioner sebagai alat penelitian untuk mengumpulkan informasi dengan tujuan untuk memberikan gambaran secara mendetail tentang karakteristik dan preferensi konsumen.

Metode pengambilan sampel dalam penelitian ini menggunakan metode systematic random sampling yaitu pengambilan sampel yang dilakukan menggunakan selang interval tertentu secara berurutan dalam selang waktu 30 menit pada penelitian ini dan didapatkan hasil sebesar 68 responden pada coffee shop kecil dan 88 responden pada coffee shop besar.

Data yang digunakan dalam penelitian ini adalah data primer yang diambil dan diolah sendiri oleh peneliti melalui wawancara kepada responden penelitian dengan menggunakan kuesioner dan data sekunder yaitu data yang diperoleh dari pihak lain seperti 
internet, jurnal, dan buku-buku yang berkaitan dengan penelitian ini.

Variabel yang diteliti dalam penelitian ini adalah:

1. Karakteristik demografi konsumen yaitu, jenis kelamin, usia, pendapatan, pekerjaan, jarak, dan waktu tempuh.

2. Karakteritsik psikografi konsumen yaitu aktivitas, minat, dan pendapat konsumen.

3. Atribut Coffee Shop menurut Koo (2003) yaitu, atmosfer, lokasi, fasilitas, layanan pramuniaga, layanan purna jual, nilai, dan produk yang ditawarkan.

Metode analisis data yang digunakan dalam penelitian ini adalah analisis deskriptif menggunakan Likert, dan analisis diskriminan menggunakan SPSS, analisis diskriminan dapat mengetahui perbedaan yang jelas antar kelompok dependen, yaitu antar coffee shop besar dan coffee shop kecil.

\section{HASIL DAN PEMBAHASAN}

\section{Karakteristik Demografi Konsumen}

Jenis kelamin konsumen yang mendominasi adalah jenis kelamin lakilaki. Menurut penelitian yang dilakukan oleh Endang Wiji Lestari, Idha Haryanto, dan Surip Mawa (2009) di Kabupaten Jember hal tersebut dikarenakan laki-laki mengonsumsi kopi lebih banyak dari perempuan yaitu sebanyak $3,83 \mathrm{~kg} /$ tahun sedangkan perempuan sekitar 1,97 $\mathrm{kg} /$ tahun.

Pengunjung yang mendominasi coffee shop besar adalah usia $18-20$ tahun, sedangkan di coffee shop kecil didominasi oleh usia $21-23$ tahun. Hal ini dikarenakan coffee shop besar terletak didekat sekolah dan universitas.

Pendapatan konsumen yang mendominasi adalah Rp.1000.000 Rp.3.000.000. Hal ini dikarenakan sebagian besar konsumen adalah pelajar dan mahasiswa yang pendapatannya terbatas.

Pekerjaan konsumen yang mendominasi adalah pelajar atau mahasiswa. Hal ini dikarenakan lokasi coffee shop yang berdekatan dengan sekolah dan universitas dan juga adanya perubahan gaya hidup. Menurut Elly Herlyana (2012) adanya fenomena pergeseran fungsi coffee shop yang kini menjual gaya hidup yang digemari oleh kaum muda, menyebabkan pelajar dan mahasiswa mencari tempat nyaman untuk mengerjakan tugas ataupun hanya sekadar mengobrol dan berkumpul bersama temannya.

Jarak yang ditempuh konsumen dari rumah ke coffee shop didominasi oleh 
konsumen yang memiliki jarak tempuh 1 $\mathrm{km}-10 \mathrm{~km}$. Hal tersebut dikarenakan konsumen coffee shop rata-rata mengunjungi coffee shop yang dekat dengan rumahnya.
Waktu yang ditempuh konsumen dari rumah ke coffee shop didominasi oleh konsumen yang memiliki waktu tempuh 21 menit - 40 menit.

Tabel 2. Karakteristik Demografi Konsumen

\begin{tabular}{|c|c|c|c|c|}
\hline \multirow[b]{2}{*}{ Variabel } & \multicolumn{4}{|c|}{ Jumlah Orang } \\
\hline & $\begin{array}{c}\text { Coffee Shop } \\
\text { Besar }\end{array}$ & $\%$ & $\begin{array}{c}\text { Coffee Shop } \\
\text { Kecil }\end{array}$ & $\%$ \\
\hline \multicolumn{5}{|l|}{ Jenis Kelamin } \\
\hline Laki-laki & 50 & $56,82 \%$ & 48 & $70,6 \%$ \\
\hline Perempuan & 38 & $43,18 \%$ & 20 & $29,4 \%$ \\
\hline \multicolumn{5}{|l|}{ Usia (Tahun) } \\
\hline$<15$ & 14 & $15,91 \%$ & - & - \\
\hline $15-17$ & 12 & $13,64 \%$ & - & - \\
\hline $18-20$ & 35 & $39,77 \%$ & 21 & $30,9 \%$ \\
\hline $21-23$ & 27 & $30,68 \%$ & 47 & $69,1 \%$ \\
\hline \multicolumn{5}{|l|}{ Pendapatan (Rp/bulan) } \\
\hline$<$ Rp. 1000.000 & 23 & $26,14 \%$ & 11 & $16,2 \%$ \\
\hline Rp.1000.000-Rp.3000.000 & 49 & $55,68 \%$ & 33 & $48,5 \%$ \\
\hline$>$ Rp.3000.000 & 16 & $18,18 \%$ & 24 & $35,3 \%$ \\
\hline \multicolumn{5}{|l|}{ Pekerjaan } \\
\hline Pelajar/Mahasiswa & 76 & $86,36 \%$ & 41 & $60,3 \%$ \\
\hline Karyawan Swasta & 5 & $5,68 \%$ & 10 & $14,7 \%$ \\
\hline PNS & - & & 3 & $4,4 \%$ \\
\hline Lainnya & 7 & $7,96 \%$ & 14 & $20,6 \%$ \\
\hline \multicolumn{5}{|c|}{ Jarak dari rumah ke coffee shop (dalam km) } \\
\hline $1 \mathrm{~km}-10 \mathrm{~km}$ & 53 & $60,23 \%$ & 31 & $45,59 \%$ \\
\hline $11 \mathrm{~km}-20 \mathrm{~km}$ & 33 & $37,5 \%$ & 22 & $32,35 \%$ \\
\hline $21 \mathrm{~km}-30 \mathrm{~km}$ & 2 & $2,27 \%$ & 13 & $19,12 \%$ \\
\hline$>30 \mathrm{~km}$ & - & - & 2 & $2,94 \%$ \\
\hline \multicolumn{5}{|c|}{ Waktu tempuh dari rumah ke coffee shop (dalam menit) } \\
\hline 1 menit -20 menit & 36 & $40,91 \%$ & 20 & $29,41 \%$ \\
\hline 21 menit -40 menit & 39 & $44,32 \%$ & 31 & $45,59 \%$ \\
\hline 41 menit -60 menit & 8 & $9,09 \%$ & 13 & $19,12 \%$ \\
\hline$>60$ menit & 5 & $5,68 \%$ & 4 & $5,88 \%$ \\
\hline
\end{tabular}

\section{Karakteristik Psikografi Konsumen dan Preferensi berdasarkan Atribut Coffee Shop}

Konsumen coffee shop besar sebagian besar memilih untuk tidak mencari pengetahuan tentang kopi, sedangkan pada coffee shop kecil sebagian besar konsumen memilih untuk mencari pengetahuan tentang kopi.

Sebagian besar konsumen coffee shop besar dan coffee shop kecil meminum kopi sebanyak 2-4 kali per minggunya. Hasil ini berbeda dengan penelitian yang dilakukan oleh Grzegorz 
Perbedaan Preferensi Konsumen Generasi Z

Maciejewski, Sylwia Mokrysz, dan Łukasz Wróblewskibahwa (2018) bahwa sebagian besar konsumen kopi di Polandia meminum kopi sebanyak 1 - 2 kali per minggu sebesar $65,1 \%$.

Rata-rata berkunjung ke coffee shop per minggu untuk coffee shop besar dan coffee shop kecil adalah 1-2 kali per minggu.

Sebagian besar konsumen coffee shop besar menghabiskan waktunya selama $>90$ menit, sedangkan sebagian besar konsumen coffee shop kecil menghabiskan waktunya selama 31-60 menit. Hal tersebut menunjukkan bahwa konsumen di coffee shop besar lebih nyaman menghabiskan waktu yang lama di coffee shop dikarenakan fasilitas yang disediakan di coffee shop besar lebih lengkap dibandingkan di coffee shop kecil.

Konsumen coffee shop besar lebih banyak memilih berkunjung ke coffee shop pada pukul 16.01-19.00, sedangkan konsumen coffee shop kecil memilih berkunjung ke coffee shop pada pukul 19.01-22.00. Hal tersebut dikarenakan pengunjung coffee shop kecil lebih banyak yang sudah bekerja dibandingkan dengan coffee shop besar seperti data yang dihasilkan pada Tabel 2 tentang karakteristik konsumen menurut pekerjaan.
Sebagian besar konsumen coffee shop besar dan coffee shop kecil memilih hangout. Hangout adalah menghabiskan waktu bersama seseorang di suatu tempat untuk bersosialisasi atau rekreasi.

Tabel 3. Psikografi Konsumen Menurut Kegiatan

\begin{tabular}{l|c|c|c|c}
\hline $\begin{array}{c}\text { Psikografi } \\
\text { Konsumen }\end{array}$ & $\begin{array}{c}\text { Coffee Shop } \\
\text { Besar }\end{array}$ & $\begin{array}{c}\text { Coffee Shop } \\
\text { Kecil }\end{array}$ \\
\hline Mencari pengetahuan tentang kopi \\
\hline Ya & 38 & $43,18 \%$ & 42 & $61,76 \%$ \\
\hline Tidak & 50 & $56,82 \%$ & 26 & $38,24 \%$ \\
\hline
\end{tabular}

\begin{tabular}{l|c|c|c|c}
\hline \multicolumn{5}{l}{ Intensitas meminum kopi per minggu } \\
\hline 1 kali & 26 & $29,55 \%$ & 9 & $13,23 \%$ \\
\hline $2-4 \mathrm{kali}$ & 40 & $40,45 \%$ & 26 & $38,24 \%$ \\
\hline $5-7 \mathrm{kali}$ & 18 & $20,45 \%$ & 20 & $29,41 \%$ \\
\hline$>7 \mathrm{kali}$ & 4 & $4,5 \%$ & 13 & $19,12 \%$ \\
\hline
\end{tabular}

Berkunjung ke coffee shop per minggu

\begin{tabular}{l|c|c|c|c}
\hline $1-2 \mathrm{kali}$ & 44 & $50 \%$ & 28 & $41,18 \%$ \\
\hline $3-4 \mathrm{kali}$ & 36 & $40,91 \%$ & 23 & $33,82 \%$ \\
\hline $5-7 \mathrm{kali}$ & 8 & $9,09 \%$ & 17 & $25 \%$ \\
\hline \multicolumn{5}{l}{ Rata-rata waktu yang dihabiskan saat } \\
berkunjung ke coffee shop (menit) \\
\hline $1-30$ & 2 & $2,27 \%$ & 4 & $5,88 \%$ \\
\hline $31-61$ & 13 & $14,77 \%$ & 24 & $35,3 \%$ \\
\hline $61-90$ & 31 & $35,23 \%$ & 23 & $33,82 \%$ \\
\hline$>90$ & 42 & $47,73 \%$ & 17 & $25 \%$ \\
\hline
\end{tabular}

Jam berkunjung ke coffee shop

\begin{tabular}{l|c|c|c|c}
\hline $10-13$ & - & - & - & - \\
\hline $13-16$ & 14 & $15,91 \%$ & 6 & $8,82 \%$ \\
\hline $16-19$ & 61 & $69,32 \%$ & 24 & $35,3 \%$ \\
\hline $19-22$ & 13 & $14,77 \%$ & 38 & $55,88 \%$ \\
\hline
\end{tabular}

Hal yang dilakukan di coffee shop selain meminum kopi

\begin{tabular}{l|c|c|c|c}
\hline Tugas & 40 & $45,45 \%$ & 28 & $41,18 \%$ \\
\hline Hangout & 44 & $50 \%$ & 33 & $48,53 \%$ \\
\hline Rapat & - & - & 7 & $10,29 \%$ \\
\hline Lainnya & 4 & $4,55 \%$ & - & - \\
\hline
\end{tabular}

Jenis metode penyeduhan yang disukai oleh sebagian besar konsumen coffee shop besar adalah espresso base, sedangkan sebagian besar konsumen coffee shop kecil menyukai manual brew.

Sebagian besar konsumen coffee shop besar dan coffee shop kecil adalah social drinker. Social drinker memiliki 
tujuan lebih dari sekedar meminum kopi jika berkunjung ke coffee shop. Oleh karena itu, mereka biasanya datang bersama teman dan jarang untuk sendirian. Social drinker menganggap minum kopi adalah gaya hidup kekinian yang memberikan rasa bangga.

Biaya yang dikeluarkan saat berkunjung ke coffee shop oleh sebagian besar konsumen coffee shop besar adalah $<$ Rp.50.000, sedangkan konsumen coffee shop kecil sebesar Rp.50.000-Rp.100.000. Hal tersebut dikarenakan sebagian besar konsumen coffee shop besar hanya ingin menikmati fasilitas ataupun suasana didalam coffee shop sehingga hanya memesan minuman ataupun makanan dengan jumlah yang sedikit dan juga banyak konsumen pelajar/mahasiswa yang pendapatannya masih terbatas, berbeda dengan coffee shop kecil yang lebih banyak orang yang sudah bekerja dibandingkan di coffee shop besar.

Sebagian besar konsumen coffee shop besar dan coffee shop kecil berkunjung ke coffee shop bersama teman atau pasangan. Konsumen coffee shop didominasi oleh pelajar atau mahasiswa dengan tipe social drinker, sehingga konsumen cenderung berkunjung ke coffee shop dengan teman atau pasangannya.

Sebagian besar konsumen coffee shop besar dan coffee shop kecil berkunjung ke coffee shop dengan 3-4 orang. Hal ini dikarenakan konsumen memilih berkunjung ke coffee shop bersama teman.

Tabel 4. Psikografi Konsumen Menurut Minat

\begin{tabular}{l|c|c|c|c}
\hline $\begin{array}{c}\text { Psikografi } \\
\text { Konsumen }\end{array}$ & \multicolumn{2}{c|}{$\begin{array}{c}\text { Coffee Shop } \\
\text { Besar }\end{array}$} & \multicolumn{2}{c}{$\begin{array}{c}\text { Coffee Shop } \\
\text { Kecil }\end{array}$} \\
\hline Jenis metode penyeduhan yang disukai \\
\hline $\begin{array}{l}\text { Espresso } \\
\text { Base }\end{array}$ & 49 & $55,68 \%$ & 28 & $41,18 \%$ \\
\hline \begin{tabular}{l|c|c|c} 
Manual Brew \\
Tipe peminum kopi
\end{tabular} & 39 & $44,32 \%$ & 40 & $58,82 \%$ \\
\hline $\begin{array}{l}\text { Pecandu } \\
\text { Kafein }\end{array}$ & 13 & $14,77 \%$ & 10 & $14,70 \%$ \\
\hline $\begin{array}{l}\text { Pemburu } \\
\text { Latte Art }\end{array}$ & 15 & $17,05 \%$ & 6 & $8,82 \%$ \\
\hline $\begin{array}{l}\text { Frappucino } \\
\text { Fanatik }\end{array}$ & 13 & $14,77 \%$ & 4 & $5,88 \%$ \\
\hline $\begin{array}{l}\text { Penyuka } \\
\text { Manual Brew }\end{array}$ & 11 & $12,5 \%$ & 22 & $32,36 \%$ \\
\hline $\begin{array}{l}\text { Social } \\
\text { Drinker }\end{array}$ & 36 & $40,91 \%$ & 26 & $38,24 \%$ \\
\hline
\end{tabular}

Biaya yang dikeluarkan saat berkunjung ke coffee shop

\begin{tabular}{l|c|c|c|c}
\hline$<$ Rp 50.000 & 43 & $48,86 \%$ & 27 & $39,71 \%$ \\
\hline $\begin{array}{l}\text { Rp. 50.000 - } \\
\text { Rp. 100.000 }\end{array}$ & 35 & $39,77 \%$ & 41 & $60,29 \%$ \\
\hline$>$ Rp. 100.000 & 10 & $11,37 \%$ & - & \\
\hline
\end{tabular}

Dengan siapa berkunjung ke coffee shop

\begin{tabular}{l|c|c|c|c}
\hline Sendiri & 9 & $10,23 \%$ & 8 & $11,77 \%$ \\
\hline Teman & 73 & $82,95 \%$ & 56 & $82,35 \%$ \\
\hline Keluarga & 6 & $6,82 \%$ & 2 & $2,94 \%$ \\
\hline Rekan Bisnis & - & & 2 & $2,94 \%$
\end{tabular}

Jumlah orang yang berkunjung ke coffee shop

\begin{tabular}{l|c|c|c|c}
\hline 1-2 orang & 15 & $17,04 \%$ & 21 & $30,88 \%$ \\
\hline 3-4 orang & 55 & $62,5 \%$ & 34 & $50 \%$ \\
\hline 5-6 orang & 17 & $19,32 \%$ & 11 & $16,18 \%$ \\
\hline$>6$ orang & 1 & $1,14 \%$ & 2 & $2,94 \%$ \\
\hline
\end{tabular}


Perbedaan Preferensi Konsumen Generasi Z

Alasan utama konsumen coffee shop besar mengunjungi coffee shop didominasi oleh atmosfer/suasana. Atmosfer adalah suasana dalam cafe yang menciptakan perasaan tertentu dalam pelanggan yang ditimbulkan dari penggunaan unsur desain interior, pengaturan cahaya, tata suara sistem pengaturan udara dan pelayanan. Alasan utama untuk konsumen coffee shop kecil didominasi oleh produk. Hal ini selaras dengan penelitian yang dilakukan oleh Gloria et al (2017) bahwa konsumen coffee shop di K8 Coffee House and Resto Manado menganggap atmosfer dan produk merupakan hal yang sangat penting bagi konsumen.

Konsumen coffee shop besar dan coffee shop kecil berniat untuk datang kembali ke coffee shop yang didatanginya.

Tabel 5. Psikografi Konsumen Menurut Pendapat

\begin{tabular}{l|c|c|c|c}
$\begin{array}{l}\text { Psikografi } \\
\text { Konsumen }\end{array}$ & $\begin{array}{c}\text { Coffee Shop } \\
\text { Besar }\end{array}$ & $\begin{array}{c}\text { Coffee Shop } \\
\text { Kecil }\end{array}$ \\
\hline Alasan utama mengunjungi coffee shop \\
\hline Atmosfer & 43 & $48,86 \%$ & 25 & $36,77 \%$ \\
\hline Layanan & - & & - & \\
\hline Produk & 15 & $17,05 \%$ & 36 & $52,94 \%$ \\
\hline Nilai & - & & - & \\
\hline Lokasi & 7 & $7,95 \%$ & 6 & $8,82 \%$ \\
\hline Fasilitas & 23 & $26,14 \%$ & 1 & $1,47 \%$ \\
\hline Berniat untuk datang kembali ke coffee shop \\
\hline Ya & 88 & $100 \%$ & 67 & $98,53 \%$ \\
\hline Tidak & - & - & 1 & $1,47 \%$ \\
\hline
\end{tabular}

Pada atribut coffee shop atmosfer sebagian besar konsumen memilih sangat penting pada suasana yang nyaman dan bersih, dan memilih penting pada display produk menarik. Kebersihan merupakan salah satu aspek penting untuk menciptakan suasana yang nyaman. Coffee shop kotor akan membuat perasaan yang menikmati makanan dan minuman di coffee shop menjadi tidak baik. Display produk menarik dapat memudahkan konsumen dalam mencari produk yang diinginkannya dan dapat menarik konsumen secara visual untuk mengunjungi coffee shop dan membeli produknya. Desain coffee shop menarik menunjukkan bahwa konsumen coffee shop besar memilih sangat penting, sedangkan untuk konsumen coffee shop kecil memilih penting.

Pada atribut coffee shop menurut lokasi menunjukkan konsumen coffee shop besar dan konsumen coffee shop kecil memilih penting pada lokasi strategis dan akses yang mudah. Lokasi tepat dan strategis menurut Koo (2003) akan menentukan kenyamanan pada konsumen. Lokasi yang strategis membantu pelanggan dengan mudah menemukan lokasi usaha. Lokasi yang strategis dibantu transportasi yang memadai juga akan menjadi nilai lebih pada restoran. 
MIMBAR AGRIBISNIS

Jurnal Pemikiran Masyarakat Ilmiah Berwawasan Agribisnis. Januari 2019. 6(1): 77-89

Tabel 6. Preferensi Konsumen berdasarkan Atribut Coffee Shop Atmosfer, Lokasi, dan Fasilitas

\begin{tabular}{|c|c|c|c|c|}
\hline \multirow[b]{2}{*}{ Tingkatan yang Disetujui } & \multicolumn{4}{|c|}{ Jumlah Orang } \\
\hline & $\begin{array}{c}\text { Coffee } \\
\text { Shop Besar }\end{array}$ & $\%$ & $\begin{array}{c}\text { Coffee Shop } \\
\text { Kecil }\end{array}$ & $\%$ \\
\hline \multicolumn{5}{|l|}{ Desain coffee shop menarik } \\
\hline Sangat Tidak Penting & - & - & - & - \\
\hline Tidak Penting & 3 & $3,41 \%$ & 8 & $11,76 \%$ \\
\hline Ragu-ragu & - & - & 21 & $30,88 \%$ \\
\hline Penting & 38 & $43,18 \%$ & 27 & $39,71 \%$ \\
\hline Sangat Penting & 47 & $53,41 \%$ & 12 & $27,65 \%$ \\
\hline \multicolumn{5}{|c|}{ Coffee shop memiliki suasana yang nyaman dan bersih } \\
\hline Sangat Tidak Penting & - & - & - & - \\
\hline Tidak Penting & - & - & - & - \\
\hline Ragu-ragu & 2 & $2,27 \%$ & 2 & $2,94 \%$ \\
\hline Penting & 10 & $11,36 \%$ & 32 & $47,06 \%$ \\
\hline Sangat Penting & 76 & $86,37 \%$ & 34 & $50 \%$ \\
\hline \multicolumn{5}{|l|}{ Display produk menarik } \\
\hline Sangat Tidak Penting & - & - & - & - \\
\hline Tidak Penting & 1 & $1,14 \%$ & 5 & $7,35 \%$ \\
\hline Ragu-ragu & 6 & $6,82 \%$ & 14 & $20,59 \%$ \\
\hline Penting & 51 & $57,95 \%$ & 27 & $39,71 \%$ \\
\hline Sangat Penting & 30 & $34,09 \%$ & 22 & $32,35 \%$ \\
\hline \multicolumn{5}{|l|}{ Lokasi coffee shop strategis } \\
\hline Sangat Tidak Penting & - & - & - & - \\
\hline Tidak Penting & 2 & $2,27 \%$ & 6 & $8,82 \%$ \\
\hline Ragu-ragu & 10 & $11,36 \%$ & 10 & $14,71 \%$ \\
\hline Penting & 40 & $45,46 \%$ & 28 & $41,18 \%$ \\
\hline Sangat Penting & 36 & $40,91 \%$ & 24 & $35,29 \%$ \\
\hline \multicolumn{5}{|c|}{ Akses mengunjungi coffee shop mudah } \\
\hline Sangat Tidak Penting & - & - & - & - \\
\hline Tidak Penting & - & - & 2 & $2,94 \%$ \\
\hline Ragu-ragu & 9 & $10,23 \%$ & 2 & $2,94 \%$ \\
\hline Penting & 43 & $48,86 \%$ & 37 & $54,41 \%$ \\
\hline Sangat Penting & 36 & $40,91 \%$ & 27 & $39,71 \%$ \\
\hline \multicolumn{5}{|c|}{ Coffee shop memiliki free wireless network } \\
\hline Sangat Tidak Penting & - & - & 4 & $5,88 \%$ \\
\hline Tidak Penting & - & - & 4 & $5,88 \%$ \\
\hline Ragu-ragu & 14 & $15,91 \%$ & 8 & $11,76 \%$ \\
\hline Penting & 21 & $23,86 \%$ & 14 & $20,59 \%$ \\
\hline Sangat Penting & 53 & $60,23 \%$ & 38 & $55,88 \%$ \\
\hline \multicolumn{5}{|c|}{ Coffee shop memiliki pendingin ruangan } \\
\hline Sangat Tidak Penting & - & - & 10 & $14,7 \%$ \\
\hline Tidak Penting & - & - & 19 & $27,95 \%$ \\
\hline Ragu-ragu & 13 & $14,77 \%$ & 21 & $30,88 \%$ \\
\hline Penting & 37 & $42,05 \%$ & 14 & $20,59 \%$ \\
\hline Sangat Penting & 38 & $43,18 \%$ & 4 & $5,88 \%$ \\
\hline \multicolumn{5}{|c|}{ Coffee shop memiliki lahan parkir yang luas } \\
\hline Sangat Tidak Penting & - & - & - & - \\
\hline Tidak Penting & 8 & $9,09 \%$ & - & - \\
\hline Ragu-ragu & 16 & $18,18 \%$ & 12 & $17,65 \%$ \\
\hline Penting & 37 & $42,05 \%$ & 38 & $55,88 \%$ \\
\hline Sangat Penting & 27 & $30,68 \%$ & 18 & $26,47 \%$ \\
\hline
\end{tabular}


Perbedaan Preferensi Konsumen Generasi Z

Pada atribut coffee shop menurut fasilitas konsumen memilih sangat penting pada free wireless network, dan memilih penting pada lahan parkir yang luas. Terdapat perbedaan pada coffee shop memiliki pendingin ruangan, konsumen coffee shop besar memilih sangat penting dan coffee shop kecil memilih ragu-ragu. Konsumen coffee shop kecil tidak terlalu mementingkan pendingin ruangan karena konsumen lebih fokus terhadap produk yang diinginkan, berbeda dengan konsumen di coffee shop besar yang ingin menikmati fasilitas yang disediakan oleh coffee shop.

Pada atribut coffee shop menurut nilai, konsumen memilih sangat penting pada harga kopi sesuai kualitas dan memilih penting pada promosi. Harga biasanya mencerminkan kualitas suatu produk, namun tidak semua harga sesuai dengan kualitas produknya, seperti terdapat beberapa produk yang memiliki kualitas rendah, tetapi dijual dengan harga yang tinggi, dan promosi penting karena konsumen dapat mengetahui tentang produknya dan memperoleh keuntungan dari promosi tersebut.

Pada atribut coffee shop menurut layanan, konsumen memilih sangat penting pada karyawan memiliki sifat ramah, jika karyawan ramah konsumen akan merasa puas dan tidak ada nilai buruk bagi coffee shop. Pada pelayanan coffee shop cepat menunjukkan bahwa konsumen coffee shop besar memilih penting, sedangkan konsumen coffee shop kecil memilih sangat penting. Konsumen coffee shop kecil merasa pelayanan cepat sangat penting dikarenakan mereka tidak berlama-lama di coffee shop dan ingin segera menikmati kopi atau produknya.

Pada atribut coffee shop menurut layanan purna, jual konsumen memilih sangat penting pada layanan coffee shop terhadap keluhan konsumen dilakukan dengan baik dikarenakan tidak setiap saat suatu produk dapat memuaskan konsumen.

Pada atribut coffee shop menurut produk yang ditawarkan, konsumen memilih sangat penting pada rasa kopi yang unik dan konsisten, dikarenakan kopi merupakan produk utama, jika kopi menjadi tidak konsisten akan rasa, harga, tekstur, aroma, dan lainnya konsumen yang mengonsumsi kopi akan kecewa dan berpotensi tidak kembali lagi ke coffee shop. 
Tabel 7. Preferensi Konsumen berdasarkan Atribut Coffee Shop Nilai, Layanan Pramuniaga, Layanan Purna Jual, dan Produk yang ditawarkan

\begin{tabular}{|c|c|c|c|c|}
\hline \multirow{2}{*}{ Tingkatan yang Disetujui } & \multicolumn{4}{|c|}{ Jumlah Orang } \\
\hline & Coffee Shop Besar & $\%$ & Coffee Shop Kecil & $\%$ \\
\hline \multicolumn{5}{|c|}{ Harga kopi sesuai dengan kualitas yang ditawarkan } \\
\hline Sangat Tidak Penting & - & - & - & - \\
\hline Tidak Penting & 2 & $2,27 \%$ & - & - \\
\hline Ragu-ragu & - & - & 1 & $1,47 \%$ \\
\hline Penting & 32 & $36,37 \%$ & 26 & $38,24 \%$ \\
\hline Sangat Penting & 54 & $61,36 \%$ & 41 & $60,29 \%$ \\
\hline \multicolumn{5}{|c|}{ Coffee shop sering mengadakan promosi } \\
\hline Sangat Tidak Penting & - & & 6 & $8,82 \%$ \\
\hline Tidak Penting & 4 & $4,55 \%$ & 13 & $19,12 \%$ \\
\hline Ragu-ragu & 24 & $27,27 \%$ & 14 & $20,59 \%$ \\
\hline Penting & 34 & $38,64 \%$ & 23 & $33,82 \%$ \\
\hline Sangat Penting & 26 & $29,54 \%$ & 12 & $17,65 \%$ \\
\hline \multicolumn{5}{|c|}{ Karyawan coffee shop memiliki sifat yang ramah } \\
\hline Sangat Tidak Penting & - & - & - & - \\
\hline Tidak Penting & - & - & - & - \\
\hline Ragu-ragu & 2 & $2,27 \%$ & 12 & $17,65 \%$ \\
\hline Penting & 31 & $35,23 \%$ & 25 & $36,76 \%$ \\
\hline Sangat Penting & 55 & $62,5 \%$ & 31 & $45,59 \%$ \\
\hline \multicolumn{5}{|l|}{ Pelayanan coffee shop cepat } \\
\hline Sangat Tidak Penting & - & - & - & - \\
\hline Tidak Penting & 2 & $2,27 \%$ & - & - \\
\hline Ragu-ragu & 6 & $6,82 \%$ & 7 & $10,29 \%$ \\
\hline Penting & 48 & $54,55 \%$ & 29 & $42,65 \%$ \\
\hline Sangat Penting & 32 & $36,36 \%$ & 32 & $47,06 \%$ \\
\hline \multicolumn{5}{|c|}{ Layanan coffee shop terhadap keluhan konsumen dilakukan dengan baik } \\
\hline Sangat Tidak Penting & - & - & - & - \\
\hline Tidak Penting & - & - & 2 & $2,94 \%$ \\
\hline Ragu-ragu & 2 & $2,27 \%$ & 6 & $8,82 \%$ \\
\hline Penting & 42 & $47,73 \%$ & 28 & $41,18 \%$ \\
\hline Sangat Penting & 44 & $50 \%$ & 32 & $47,06 \%$ \\
\hline \multicolumn{5}{|c|}{ Rasa kopi yang unik dan konsisten } \\
\hline Sangat Tidak Penting & - & - & - & - \\
\hline Tidak Penting & - & - & - & - \\
\hline Ragu-ragu & 8 & $9,09 \%$ & 4 & $5,88 \%$ \\
\hline Penting & 34 & $38,64 \%$ & 20 & $29,41 \%$ \\
\hline Sangat Penting & 46 & $52,27 \%$ & 44 & $64,71 \%$ \\
\hline
\end{tabular}

Perbedaan

Karakteristik

Preferensi
dengan

dan

Diskriminan

Terdapat perbedaan signifikan

pada karakteristik usia, intensitas minum kopi per minggu, rata-rata waktu di coffee shop, dan jam berkunjung ke coffee shop.
Tabel 8. Variabel Entered

\begin{tabular}{c|l|c}
\hline Step & \multicolumn{1}{|c}{ Entered } & \multicolumn{1}{c}{ Sig. } \\
\hline 1 & Usia & .000 \\
\hline 2 & $\begin{array}{l}\text { Waktu di Coffee } \\
\text { Shop }\end{array}$ & .000 \\
\hline 3 & $\begin{array}{l}\text { Intensitas Minum } \\
\text { Kopi Per minggu }\end{array}$ & .000 \\
\hline 4 & $\begin{array}{l}\text { Jam berkunjung ke } \\
\text { coffee shop }\end{array}$ & .000 \\
\hline
\end{tabular}


Perbedaan Preferensi Konsumen Generasi Z

Berdasarkan Tabel 8 di atas diperoleh nilai sig. output variabel adalah 0,000. Keempat variabel tersebut mempunyai nilai sig. $<0,05$ sehingga variabel tersebut dapat digunakan untuk mengidentifikasi perbedaan antar kategori.

Tabel 9. Classification Result

\begin{tabular}{c|c|c|c}
\hline $\begin{array}{c}\text { Klasifikasi } \\
\text { Coffee } \\
\text { Shop }\end{array}$ & $\begin{array}{c}\text { Coffee } \\
\text { Shop } \\
\text { Kecil }\end{array}$ & $\begin{array}{c}\text { Coffee } \\
\text { Shop } \\
\text { Besar }\end{array}$ & Total \\
\hline $\begin{array}{c}\text { Coffee } \\
\text { Shop } \\
\text { Kecil }\end{array}$ & 55 & 13 & 68 \\
\hline $\begin{array}{c}\text { Coffee } \\
\text { Shop } \\
\text { Besar }\end{array}$ & 18 & 70 & 88 \\
\hline $\begin{array}{c}\text { Coffee } \\
\text { Shop } \\
\text { Kecil }\end{array}$ & $80.9 \%$ & $19.1 \%$ & $100 \%$ \\
\hline $\begin{array}{c}\text { Coffee } \\
\text { Shop } \\
\text { Besar }\end{array}$ & $20.5 \%$ & $79.5 \%$ & $100 \%$ \\
\hline
\end{tabular}

Tabel di atas menunjukkan kolom original untuk coffee shop kecil sebanyak 55 responden atau 80,9\%, sedangkan coffee shop besar 70 responden atau $79,5 \%$.

Ketepatan fungsi diskriminan dicari dengan cara :

$$
\frac{55+70}{156}=0,801
$$

Hasil yang didapatkan adalah 0,801 atau $80 \%$, maka ketepatan tinggi karena mendekati angka $100 \%$.

\section{KESIMPULAN DAN SARAN}

Perbedaan karakteristik dan preferensi konsumen coffee shop besar dan coffee shop kecil terdapat pada variabel usia, mencari pengetahuan tentang kopi, metode penyeduhan yang disukai, waktu di coffee shop, jam berkunjung ke coffee shop, indikator utama mengunjungi coffee shop, dan terdapat perbedaan kepentingan pada indikator desain coffee shop menarik, coffee shop memiliki pendingin ruangan, dan pelayanan coffee shop cepat. Perbedaan yang signifikan menggunakan alat analisis diskriminan pada coffee shop kecil dan coffee shop besar terdapat pada variabel usia, intensitas minum kopi, waktu di coffee shop, dan jam berkunjung ke coffee shop.

Saran untuk Essay Coffee sebaiknya menyesuaikan segmentasi konsumen dengan karakteristik yang mendominasi yaitu dengan menambah variasi menu manual brew, buka pada sore hari hingga malam hari dan fokus mengembangkan coffee shop pada atribut yang dianggap sangat penting oleh konsumen, yaitu dengan membuat suasana yang nyaman dan bersih, meningkatkan kinerja free wireless network, mempertahankan sifat karyawan yang ramah, kecepatan pelayanan coffee shop ditingkatkan, 
meningkatkan kualitas produk, layanan terhadap keluhan konsumen dilakukan dengan baik, dan mempertahankan rasa kopi yang unik dan kosisten.

Saran untuk Lo.Ka.Si Coffee and Space sebaiknya menyesuaikan segmentasi konsumen dengan karakteristik yang mendominasi yaitu menambah variasi menu espresso base, dan fokus mengembangkan coffee shop pada atribut yang dianggap sangat penting oleh konsumen, yaitu mengembangkan desain coffee shop agar tambah menarik konsumen, mempertahankan dan menciptakan suasana yang nyaman dan bersih, meningkatkan kinerja free wireless network, menambah atau meningkatkan kinerja pendingin ruangan, mempertahankan sifat karyawan yang ramah, meningkatkan kualitas produk, layanan terhadap keluhan konsumen dilakukan dengan baik, dan mempertahankan rasa kopi yang unik dan kosisten.

\section{DAFTAR PUSTAKA}

Fuad, M., H, C., Nurlela, Sugiarto, \& Y.E.F, P. (2001). Pengantar Bisnis. PT. Gramedia Pustaka.
Herlyana, E. (2012). Fenomena Coffee Shop Sebagai Gejala Gaya Hidup Baru Kaum Muda. ThaqÃfiyyz̃T, 13(1), 188-204.

International Coffee Organization. (2018). World Coffee Consumption. Retrieved from http://www.ico.org/prices/newconsumption-Tabel.pdf

Koo, D. M. (2003). Inter-relationships among store images, store satisfaction, and store loyalty among Korea discount retail patrons. In Asia Pacific Journal of Marketing and Logistics (Vol. 15). https://doi.org/10.1108/1355585031 0765033

Lestari, Endang Wiji; Haryanto, Idha; Mawa, S. (2009). Tingkat Konsumsi Kopi Domestik dan Faktor-faktor yang Mempengaruhi pada Masyarakat Perkotaan di Kabupaten Jember.

Mokrysz, S. (2016). Consumer preferences and behaviour on the coffee market in Poland. Forum Scientiae Oeconomia, 4(4), 91-108.

Santosa, E. T. (2015). Raising Children in Digital Era. Jakarta: PT. Elex Media Komputindo.

Warokka, G. F., Pangemanan, S. S., \& Worang, F. G. (2017). Analyzing Restaurant Attributes of K8 Coffee House and Resto in Manado Using Importance Performance Analysis. Jurnal EMBA: Jurnal Riset Ekonomi, Manajemen, Bisnis Dan Akuntansi, 5(3). 